NASA Technical Memōrandum 102379

\title{
Plasma-Deposited Amorphous Hydrogenated Carbon Films and Their Tribological Properties
}

Kazuhisa Miyoshi, John J. Pouch, and Samuel A. Alterovitz Lewis Research Center

Cleveland, Ohio

October 1989

\section{N/SA}

(NASA-TM-102379) PLASMA-DEPUSITED AMORPHOUS HYDPOGENATED CARENN FILMS AND THETR TRIROLOGICAL PROPERTIFS (NASA) $13 \mathrm{p}$

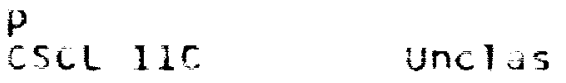




\title{
PLASMA-DEPOSITED AMORPHOUS HYDROGENATED CARBON FILMS AND THEIR TRIBOLOGICAL PROPERTIES
}

\author{
Kazuhisa Miyoshi, John J. Pouch, and Samuel A. Alterovitz \\ National Aeronautics and Space Administration \\ Lewis Research Center \\ Cleveland, Ohio 44135
}

\begin{abstract}
Recent work on the properties of "diamondlike" carbon films and their dependence on preparation conditions are reviewed. The results of the study indicate that plasma deposition enables one to deposit a variety of amorphous hydrogenated carbon $(\mathrm{a}-\mathrm{C}: \mathrm{H})$ films exhibiting more diamondlike behavior to more graphitic behavior. The plasmadeposited $\mathrm{a}-\mathrm{C}: \mathrm{H}$ can be effectively used as hard, wear-resistant, and protective lubricating films on ceramic materials such as $\mathrm{Si}_{3} \mathrm{~N}_{4}$ under a variety of environmental conditions such as moist air, dry nitrogen, and vacuum.
\end{abstract}

\section{INTRODUCTION}

Carbon films exhibiting unique properties can be formed on different substrates by ion-beam deposition, ion-beam sputtering, and plasma deposition of gaseous hydrocarbons [1 to 8]. The properties are sensitive to the deposition conditions. These resulting films can exhibit high electrical resistivity, semitransparency, mechanical hardness, and chemical inertness. The carbon films show promise as wear-resistant, hard solid lubricating coatings for mechanical systems such as bearings and optical components. In addition, carbon films are useful as gate dielectrics and passivating layers in semiconductor device processing, insulators for metal-insulator-metal fabrication, and masks for nanometer lithography [9 to 11$]$.

This chapter is principally concerned with the chemical, physical, and tribological characteristics of amorphous hydrogenated carbon (a-C:H) films grown on different substrates $\left(\mathrm{Si}_{3} \mathrm{~N}_{4}, \mathrm{GaAs}\right.$, InP, $\mathrm{Si}$, and fused silica) by means of plasma chemical vapor deposition at $30 \mathrm{kHz}$. The influence of growth conditions on the chemical and physical properties of these films was studied by Auger electron spectroscopy (AES), secondary ion mass spectroscopy (SIMS), $\mathrm{x}$-ray photoelectron spectroscopy (XPS), ellipsometry, and $\mathrm{N}^{15}$ nuclear reaction techniques. The nuclear reaction techniques provide the hydrogen concentration information. These analysis techniques and procedures are described in references 12 to 18 . Tribological studies have also been conducted with the $\mathrm{a}-\mathrm{C}: \mathrm{H}$ films to better understand those chemical and physical properties of the films that will affect their tribological behavior when in contact with a ceramic material. The friction, wear, and lubricating behavior of the a-C:H films were examined with flat specimens (composed of an a-C:H film and $\mathrm{Si}_{3} \mathrm{~N}_{4}$ substrate) in contact with $\mathrm{Si}_{3} \mathrm{~N}_{4}$ riders in two processes. The first was done in dry nitrogen gas in moist air to determine the environmental effects on friction and resistance to wear of the a-C:H films. The second was done in an ultrahigh vacuum system to determine the effect of temperature on adhesion and friction of a-C:H films. 


\section{AMORPHOUS HYDROGENATED CARBON (a-C:H) FILMS}

$\underline{\text { Plasma Deposition }}$

Amorphous hydrogenated carbon films were formed on the different substrates from the $30 \mathrm{kHz}$ ac glow discharge by using a planar plasma reactor [12 to 18]. All substrate materials were first cleaned in acetone and ethanol baths and then rinsed in deionized water. The substrates were placed on the ground anode of the parallel plate reactor in the chamber; the upper electrode was capacitively coupled to the $30 \mathrm{kHz}$ power source. The background pressure was typically $2.7 \mathrm{~Pa}$ (20 mtorr). The gas sources were $\mathrm{CH}_{4}$ and $\mathrm{C}_{4} \mathrm{H}_{10}$ (methane and butane, 99.97 percent pure). The deposition gas $\left(\mathrm{CH}_{4}\right.$ or $\left.\mathrm{C}_{4} \mathrm{H}_{10}\right)$ was used to flush the system three times prior to each run. The chamber pressure was controlled by the input gas flow rate and pumping speed. The power density and flow rate settings covered the ranges 0.4 to $5 \mathrm{~kW} \mathrm{~m}{ }^{-2}$ ( 25 to $300 \mathrm{~W}$ ) and 3 to $9 \times 10^{-5} \mathrm{~m}^{3} \mathrm{~min}^{-1}$ ( 30 to $90 \mathrm{SCCM}$ ), respectively. The initial substrate temperature was $25^{\circ} \mathrm{C}$, and it increased a few degrees during each deposition.

The film growth rate varied monotonically with deposition power. Figure I illustrates the typical dependence of growth rate on deposition power. The specimens are a-C:H films grown on InP substrates using a $\mathrm{CH}_{4}$ flow rate of $70 \mathrm{SCCM}$. This growth rate increases from 5 to $27 \mathrm{~nm} \mathrm{~min}^{-1}$ as the power increases from 25 to $300 \mathrm{~W}$.

\section{Film Characteristics}

The AES and XPS measurements indicated that the a-C:H films contained only carbon; no other element was observed to the detection limits $(0.1$ at. \%) of the instrument [12 and 13]. Figure 2 shows a typical AES profile of a-C:H films on the $\mathrm{InP}$ and GaAs. Oxygen was not present in the films, but there was a small percentage of oxygen at the carbon-InP interface. This suggests that the $\mathrm{CH}_{4}$ (methane) plasma removes all of the native oxides from the GaAs surfaces and most of it from the InP surfaces.

Relative counts of hydrocarbon ions sputtered from a-C:H films deposited on the InP substrate were determined by means of SIMS depth-profiling studies performed with $3 \mathrm{keV} \mathrm{Ar}^{+}$ions [12]. In figure 3(a) the distribution of ion counts is plotted as a function of mass-to-charge ratio for various deposition conditions using a $\mathrm{C}_{4} \mathrm{H}_{10}$ plasma. The predominant ion is $\mathrm{CH}^{+}$; it is interesting that a higher $\mathrm{CH}^{+}$level is obtained from films produced at the higher power densities. Additional ions are presented in figure 3(a): $\mathrm{CH}_{2}^{+}, \mathrm{CH}_{3}^{+}, \mathrm{C}_{2} \mathrm{H}^{+}, \mathrm{C}_{2} \mathrm{H}_{2}^{+}$, and $\mathrm{C}_{2} \mathrm{H}_{3}^{+}$.

The ion distributions extracted from a-C: $\mathrm{H}$ films prepared by a $\mathrm{CH}_{4}$ (methane) discharge are shown in figure 3 (b). Evidently, $\mathrm{CH}^{+}$has a higher probability of being sputtered from each film. At 50 SCCM (32.7 Pa), more $\mathrm{CH}^{+}$is generated from the a-C:H deposit made at $2.45 \mathrm{~kW} \mathrm{~m}^{-2}$. In addition, some of the films obtained from the $\mathrm{C}_{4} \mathrm{H}_{10}$ discharge (fig. 3(a)) have higher amounts of incorporated $\mathrm{C}_{2} \mathrm{H}_{3}$ relative to the $\mathrm{CH}_{4}$-derived films (fig. 3(b)). Figure 3 indicates that the lowest populations are associated with $\mathrm{CH}_{3}^{+}$. The ion distributions thus reflect some of the bonding arrangements that result from the interaction of the plasma radicals with the growing film [19 to 21].

A SIMS depth profile ( $3 \mathrm{keV} \mathrm{Ar}{ }^{+}$ions) of carbon deposited onto $\mathrm{GaAs}$ using $\mathrm{C}_{4} \mathrm{H}_{10}$ is presented in figure 4 . The $\mathrm{CH}_{x}^{+}(x=0,1,2,3)$ distributions are uniform in the bulk of the film, and they drop to lower levels in the vicinity

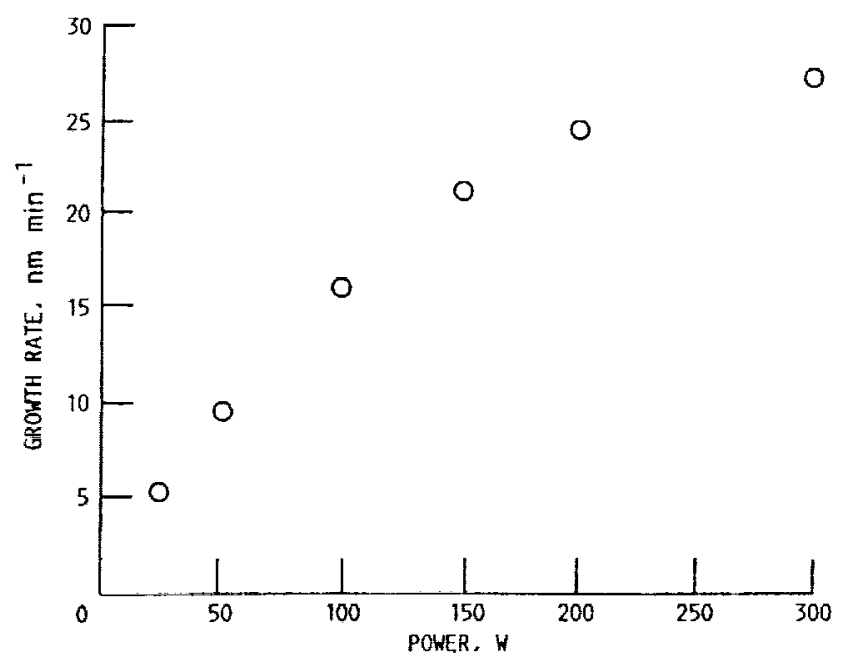

Figure 1.-Growth rate of hydrogenated carbon on $n$-InP as function of deposition power 


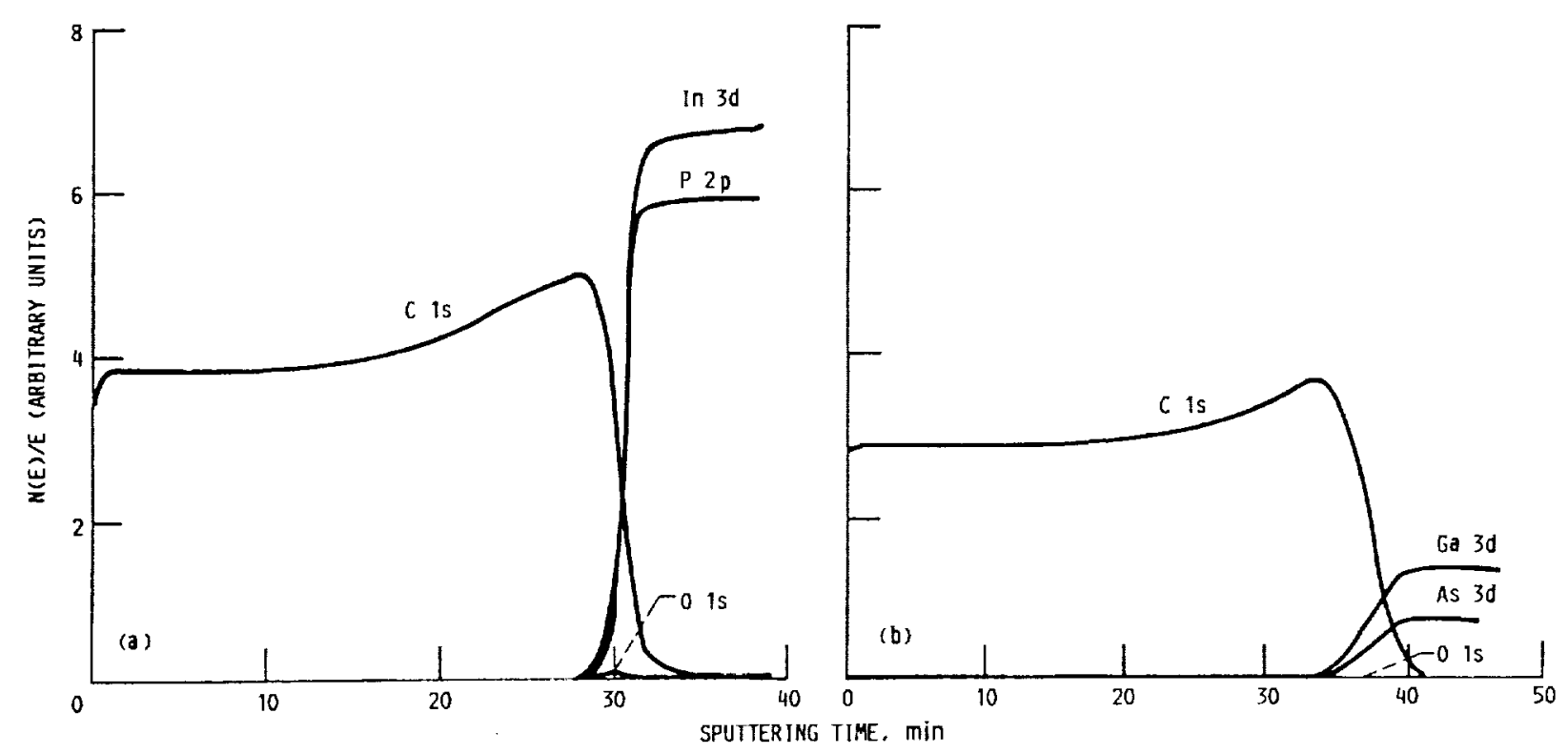

(a) $\operatorname{In} P$

(b) GaAs.

Figure 2.-Auger electron spectroscopy (AES) profiles of carbon films on InP and GaAs, using $25 \mathrm{~mA} 3 \mathrm{keV}$ Ar ${ }^{+}$ions.

of the carbon-GaAs interface. Moreover, figure 4 shows oxygen to be present throughout the film. This determination cannot be made with the less-sensitive AES technique. It is apparent that $\mathrm{Ga}^{+}$and $\mathrm{As}^{+}$are readily detected as the carbon film is sputtered away.

The argon ion etching rate of the a-C:H films is shown as a function of deposition power in figure 5(a). An inverse relationship between argon ion etching rate and deposition power is observed. The etching rate drops from 80 to $50 \mathrm{~nm} \mathrm{~min}{ }^{-1}$ when the deposition power is increased from 25 to $300 \mathrm{~W}$. This suggests that films grown at higher powers are denser than those grown at lower powers. Figure 5(b) shows the nuclear reaction analyses data. The hydrogen concentration in the carbon film decreases slightly with increasing power. The hydrogen concentrations are in the 7.2 to $7.7 \times 10^{22} \mathrm{~cm}^{-3}$ range, which gives an approximate value of 0.8 for $x$ in the formula $\mathrm{CH}_{x}$.

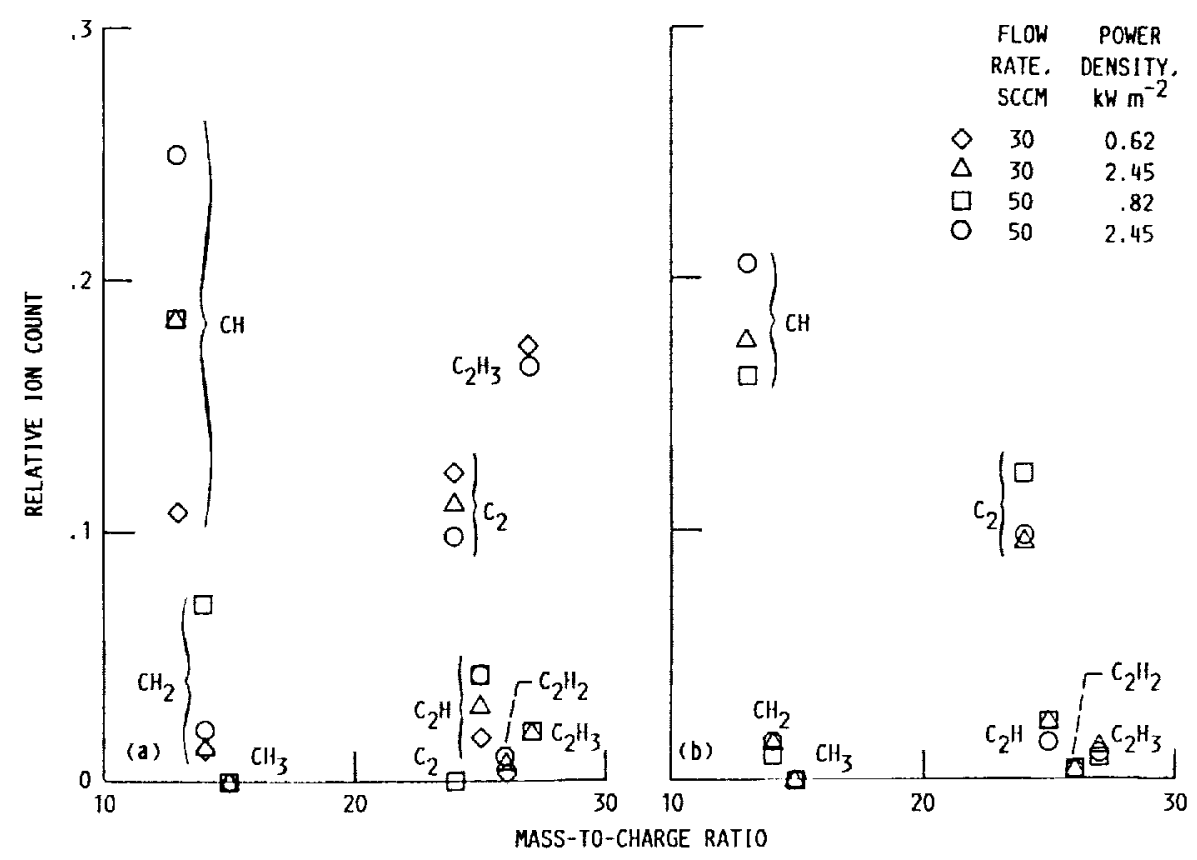

(a) $\mathrm{C}_{4} \mathrm{H}_{\mathrm{I} 0}$ plasma.

(b) $\mathrm{CH}_{4}$ plasma.

Figure 3.-Relative ion count as function of mass-to-charge ratio for carbon deposited onto InP using $\mathrm{C}_{4} \mathrm{H}_{10}$ and $\mathrm{CH}_{4}$ plasmas. 


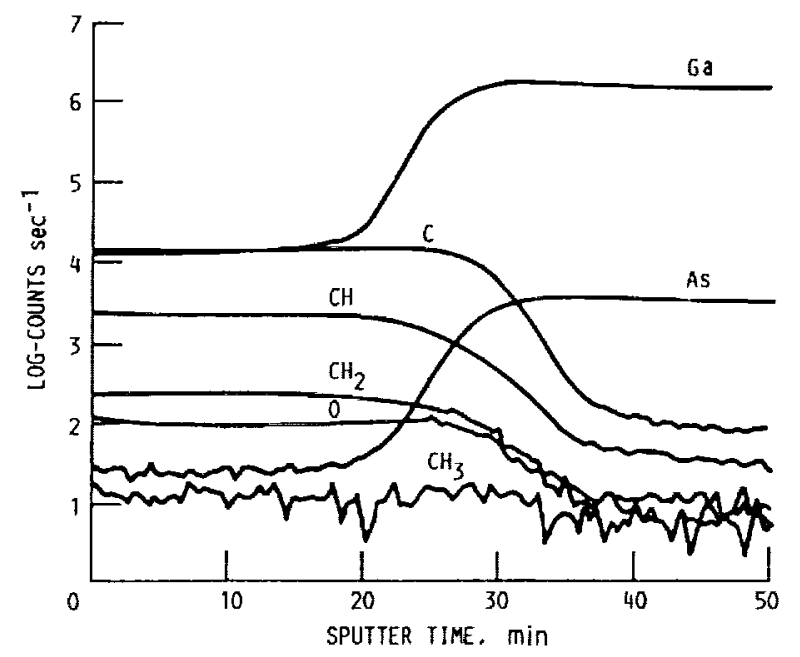

Figure 4.-Secondary ion mass spectroscopy (SIMS) depth profile of carbon on GaAs using $3 \mathrm{keV} \mathrm{Ar+ion} \mathrm{bombardment.}$
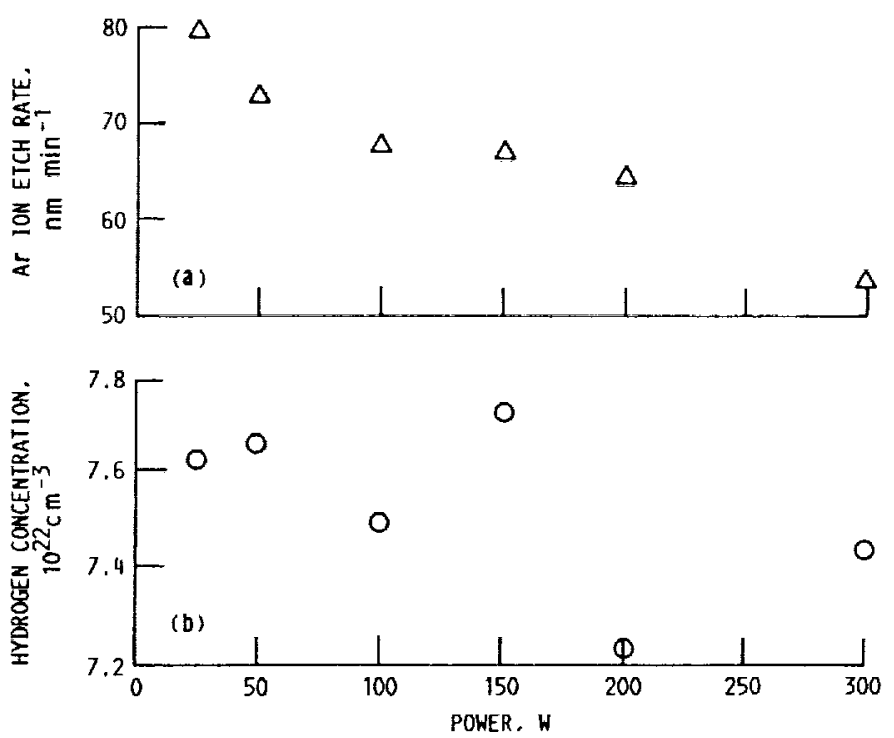

(a) Ar ion etch rate.

(b) Hydrogen concentration.

Figure 5.-Ar ion etching rate and hydrogen concentration as function of deposition power for carbon film grown on $n$-InP.

TABLE I. -COMPOSITION AND PROPERTIES OF HOT-PRESSED SILICON NITRIDE

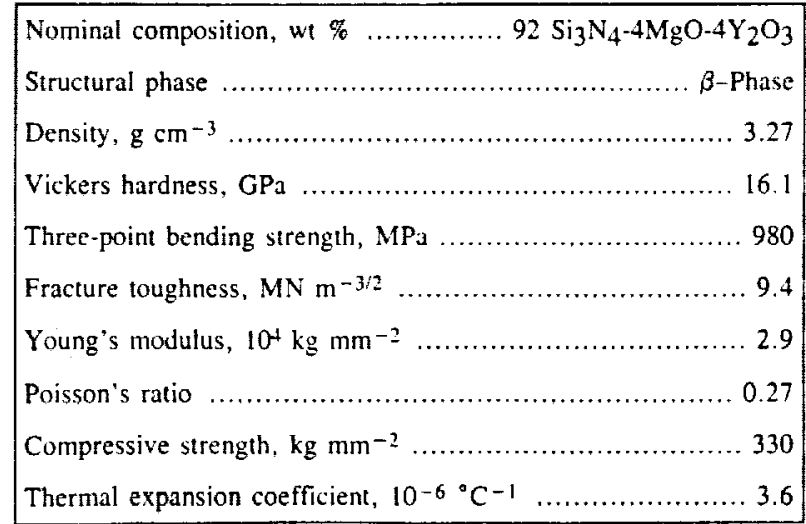




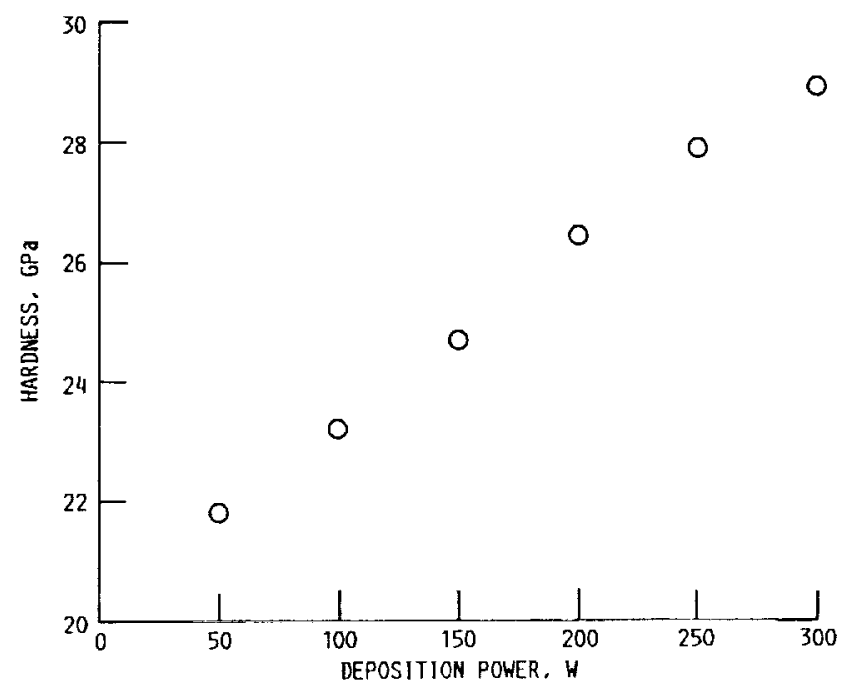

Figure 6. - Vickers hardness as function of deposition power for a-C:H film deposited on $\mathrm{Si}_{3} \mathrm{~N}_{4}$ (hardness measuring load. $0.25 \mathrm{~N}$ : hardness of $\mathrm{Si}_{3} \mathrm{~N}_{4}$ substrate, $17.1 \mathrm{GPa}$ ).

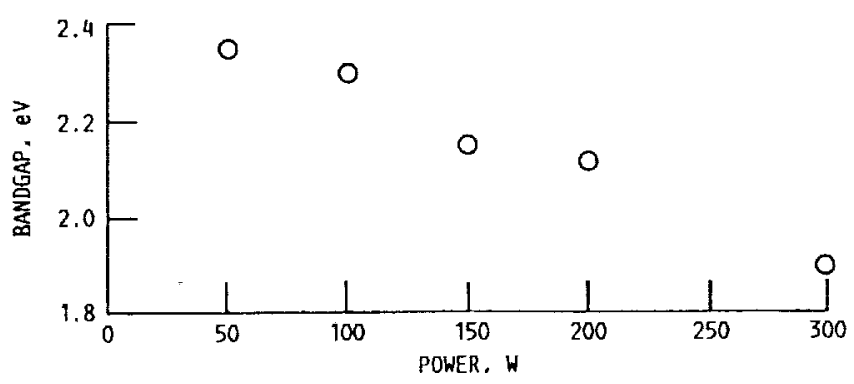

Figure 7.-Optical bandgap as function of deposition power for carbon film grown on $n$-InP

The microhardness data measured for the carbon films on $\mathrm{Si}_{3} \mathrm{~N}_{4}$ substrate (table I) at various deposition powers are presented in figure 6 . The microhardness increases as the power increases. Thus it appears that a decrease in hydrogen concentration is accompanied by an increase in film density and/or $\mathrm{c}-\mathrm{c}$ bondings, and in hardness.

The optical energy gap is shown as a function of the deposition power in figure 7 . A decrease in the optical energy gap is clearly observed with increasing power.

At this stage, we will compare our results with conjecture forwarded by S. Kaplan et al. [22]. They claim that since double-bond hydrogenation is an exothermic process, "graphitic" behavior is favored over tetrahedral bonding in higher energy growth environments. They show evidence of this assumption by comparing a-C:H films made by five different experimental configurations. As a-C: $\mathrm{H}$ properties are dependent quite strongly on the many variables encountered in different preparation conditions, it seems that a better test of this assumption is in order. In addition, their results show a rather striking feature: a-C:H films exhibiting more "diamondlike" behavior (i.e., larger bandgap and more tetrahedral bonding) show a steep decrease in their hardness as compared with the more "graphitic" films. Our results confirm this model, including the hardness measurements. The higher the plasma deposition power, the more $s p^{2}$ versus $s p^{3}$ bonds are made, giving a more "graphitic" film, with smaller bandgap (fig. 7) and higher density and hardness (figs. 5 and 6 , respectively).

\section{TRIBOLOGICAL PROPERTIES}

In the preceding section there have been indications that $\mathrm{a}-\mathrm{C}: \mathrm{H}$ films have diamondlike behavior in lower energy growth environments as compared with the more graphitic behavior in higher energy growth environments. Therefore, the objective of this section is to compare the tribological properties of a-C:H films made by different deposition powers. 
Sliding friction and wear experiments were conducted with a-C:H films deposited on $\mathrm{Si}_{3} \mathrm{~N}_{4}$ flats in contact with hemispherical $\mathrm{Si}_{3} \mathrm{~N}_{4}$ riders (1.6 mm in radius). The a-C:H films on the $\mathrm{Si}_{3} \mathrm{~N}_{4}$ flat substrates were approximately $0.06 \mu \mathrm{m}$. The $\mathrm{Si}_{3} \mathrm{~N}_{4}$ used for flat substrates and hemispherical riders was hot pressed, and its composition and some of its properties are presented in table I. Two types of sliding friction experiments were conducted with the a-C:H films [23 to 25]. The first type was conducted in nitrogen and laboratory air atmospheres with a load of $1 \mathrm{~N}$ (Hertzian contact pressure, $910 \mathrm{MPa}$ ) and at a sliding velocity of $8 \mathrm{~mm} \mathrm{~min}^{-1}$ at room temperature. The specimen rider was made to traverse on the surface of a-C:H film. The motion was reciprocal. The a-C:H films were subjected to multipass sliding by the $\mathrm{Si}_{3} \mathrm{~N}_{4}$ riders. The second type was conducted in ultrahigh vacuum $\left(10^{-8}\right.$ to $10^{-9}$ torr) with loads up to $1.7 \mathrm{~N}$ (Hertzian contact pressure, $1.5 \mathrm{GPa}$ ) and at a sliding velocity of $3 \mathrm{~mm} \mathrm{~min}^{-1}$ at temperatures up to $700{ }^{\circ} \mathrm{C}$. In this case, the a-C:H films were subjected to single-pass sliding by the $\mathrm{Si}_{3} \mathrm{~N}_{4}$ riders.

\section{Environmental Effects on Friction and Wear}

Environment significantly changes the friction and wear behavior of solid materials. Friction and wear of a-C:H films are consistent with this generality and depend on water vapor [1 and 26 to 28].

Figure 8 presents typical plots of the coefficient of friction for plasma-deposited a-C:H films at low (50 W) and high $(250 \mathrm{~W})$ deposition power as a function of the number of repeated passes in dry nitrogen and humid air environments. The values of coefficient of friction given are typical, but the trends with number of passes are quite reproducible. With the $50-\mathrm{W}$ plasma-deposited a-C:H films, the coefficient of friction was generally found to increase,

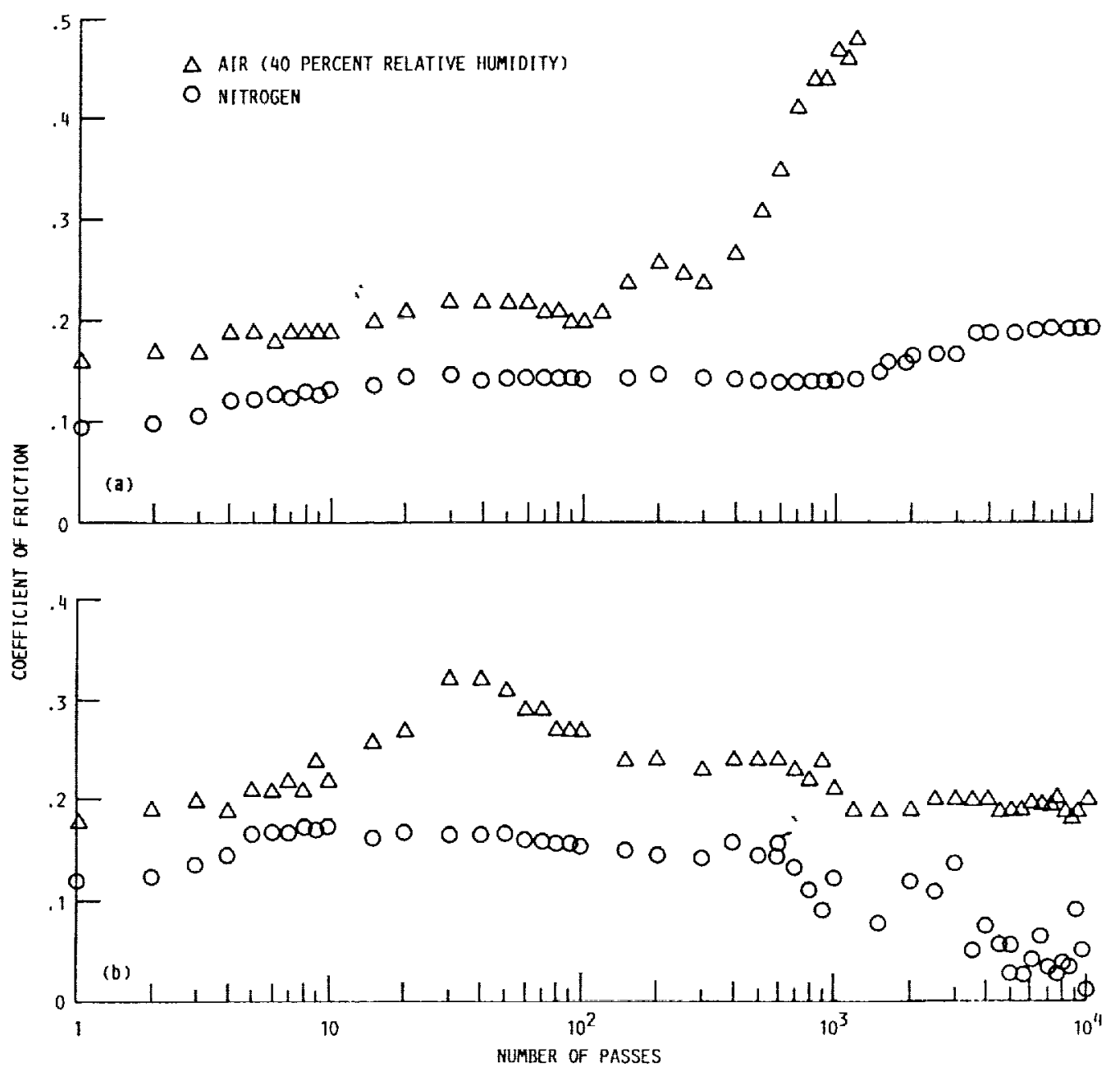

(a) Deposition power, $50 \mathrm{~W}$.

(b) Deposition power, $250 \mathrm{~W}$

Figure 8.-Average coefficient of friction as function of number of passes of $\mathrm{Si}_{3} \mathrm{~N}_{4}$ rider across a-C:H film surface in laboratory air and in dry nitrogen at deposition powers of 50 and $250 \mathrm{~W}$. 
as shown in figure 8(a). This increase, however, was small in a dry nitrogen environment even after it had been in contact with the rider for about 10000 passes. On the other hand, in humid laboratory air a significant increase in the coefficient of friction occurred at about 500 passes and increased sharply to 1000 passes. The sliding action caused breakthrough of the film and removed it from the sliding contact area at about 1000 passes. Note that among the a-C:H films deposited at various deposition powers $(50$ to $300 \mathrm{~W})$, the film deposited at $50 \mathrm{~W}$ has the lowest initial coefficient of friction $(0.08$ to 0.09$)$ in the dry nitrogen environment. The value of the coefficient of friction was similar to that of a hemispherical diamond pin (radius, $0.2 \mathrm{~mm}$ ) in sliding contact with a $\mathrm{Si}_{3} \mathrm{~N}_{4}$ flat. The friction of the diamond was low $(0.05$ to 0.1$)$ in dry nitrogen. It is well known that diamond has a low coefficient of friction in contact with various types of materials [29].

With the 250-W plasma-deposited a-C:H films (fig. 8(b)), although the coefficient of friction increased with increasing number of passes for about 10 passes in the dry nitrogen environment, it generally decreased in the range 10 to 10000 passes.

At 600 to 700 passes, the coefficients of friction became very erratic and variable, as presented in figure $8(\mathrm{~b})$. Optical microscopic examination indicated that some wear debris particles formed in the front region of the rider and on the wear track of the a-C:H film. Thus the wear particles so produced were caught up in the sliding mechanism and affected the coefficient of friction.

At 1000 passes and above, the coefricient of friction became low, but still variable $(0.01$ to 0.1$)$. At this range the coefficients of friction for the 250 -W plasma-deposited film were lower than those for the film deposited at $50 \mathrm{~W}$.

In a humid air environment, the coefficients of friction for the $250-\mathrm{W}$ plasma-deposited a-C:H film were higher as compared with those in dry nitrogen by a factor of 1.5 to 3 up to 10000 passes. The film, however, did not wear off from the substrate even in the humid air environment.

Thus, water vapor greatly increases friction and reduces the wear life of plasma-deposited a-C:H film at low deposition powers. In general, a-C:H films deposited with lower deposition powers were more susceptible to water vapor, when compared with the films deposited with higher deposition power. Particularly, the deposition power greatly affects the wear life of the films in a humid air environment. The greater the deposition power (the more graphitic the film), the greater the wear life in humid air.

\section{Annealing Effects on Friction and Wear}

Thermal annealing significantly affects the properties of a-C:H films. For example, an abrupt decrease of the optical bandgap has been observed for the thermal annealing process [14].

Figure 9 presents the optical bandgap of the a-C:H films deposited on the quartz substrates by using 150-W, 70-SCCM-flow-rate $\mathrm{CH}_{4}$ plasma as a function of annealing time at 400 and $600{ }^{\circ} \mathrm{C}$. The thermal processing of the films was accomplished in nitrogen gas with tungsten halogen light. The main part of the reduction in the optical bandgap is obtained at short annealing time. This fact can also be deduced by the result obtained by laser annealing [30],

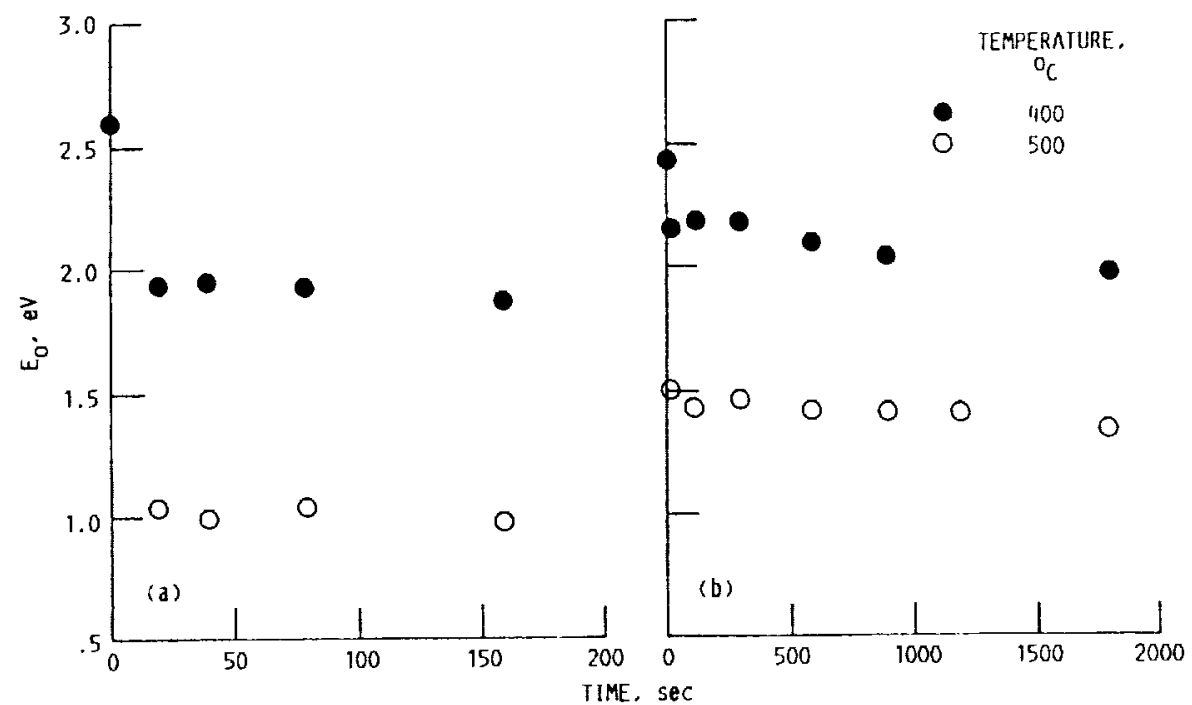

(a) Short annealing time.

(b) Long annealing time.

Figure 9.-Optical energy gap $E_{o}$ as function of annealing time for a-C:H films on quartz annealed at two temperatures. 
when processing time is much shorter than that reported here. The mechanism involved should be a two-step process. There is known to be a two-stage pyrolysis of organic material into graphite [31] for temperatures in this range, namely carbonization and polymerization. The carbonization stage includes loss of volatile matter, which we identify with hydrogen loss in this case [1]. This stage occurs in the temperature range 400 to $600{ }^{\circ} \mathrm{C}$ in a-C:H. The polymerization stage includes the formation of graphitic crystallites or sheets. If we assume that the polymerization is a diffusion-dependent process with a relatively long time constant (on the order of $10^{3} \mathrm{sec}$ ), then we can deduce that the two processes of carbonization and polymerization occur simultaneously in our a-C:H films. The abrupt decrease of the bandgap versus time at very short processing time is due to the hydrogen loss, while the subsequent decrease in optical bandgap is due to an increase in cluster size [31].

Further, absorption in the UV-visible range was measured with a-C:H films on quartz substrates [14]. The absorbance-versus-wavelength plot at $600^{\circ} \mathrm{C}$ shows a decrease in peak height and a shift in the peak position. The shift indicates changes in the carbon bonding. The decrease in peak height is attributed mostly to loss of material in this case.

Thermal annealing also changes the friction and wear characteristics of a-C:H films. Figure 10 presents the friction data for annealed a-C:H films in sliding contact with $\mathrm{Si}_{3} \mathrm{~N}_{4}$ riders in dry nitrogen and humid air environments. The

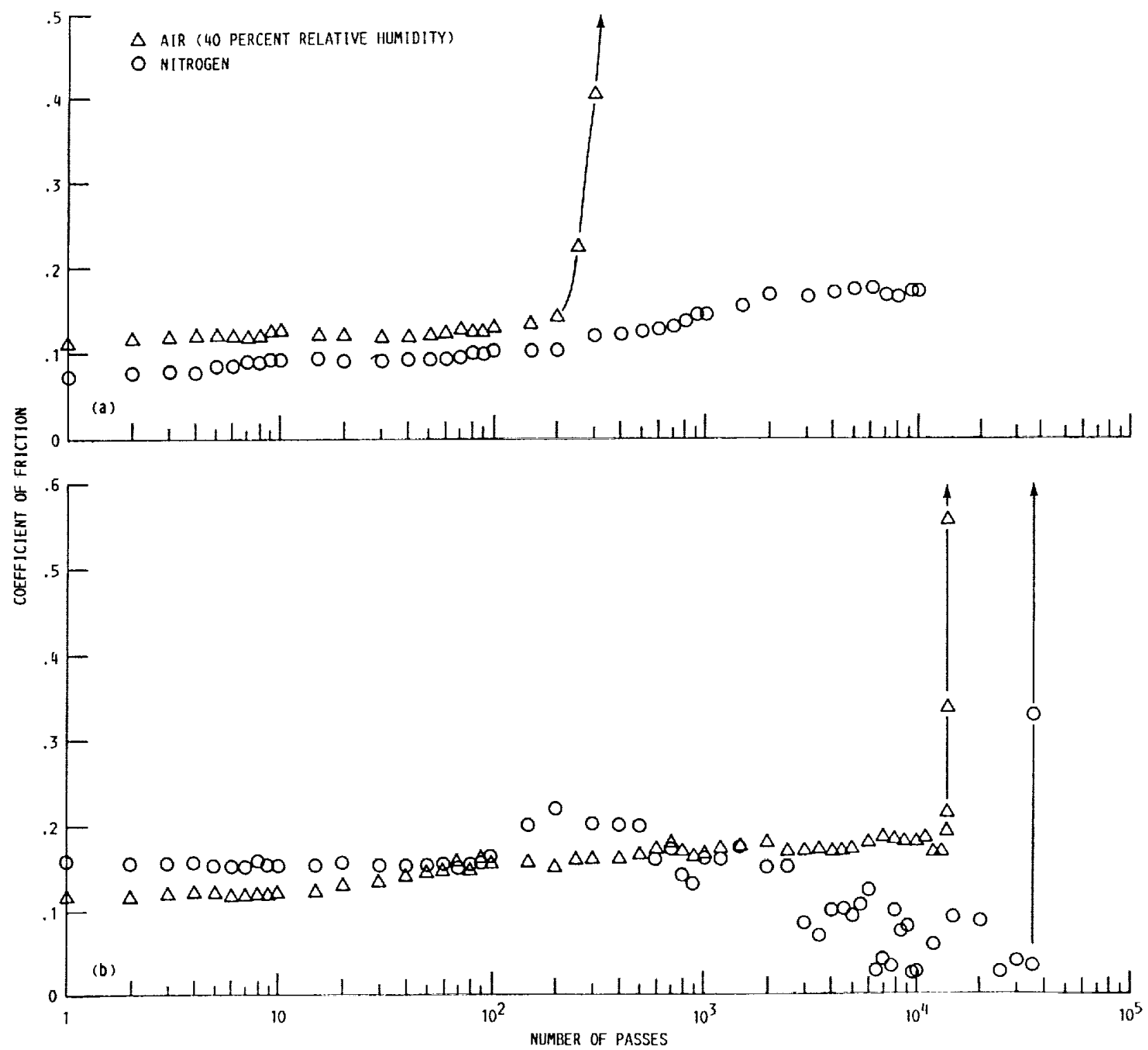

(a) Deposition power, $150 \mathrm{~W}$

(b) Deposition power, $300 \mathrm{~W}$.

Figure 10.-Average coefficient of friction as function of number of passes of $\mathrm{Si}_{3} \mathrm{~N}_{4}$ rider across a-C:H film surface in laboratory air and in dry nitrogen, after annealing a-C:H in vacuum at $700^{\circ} \mathrm{C}$, at deposition powers of 150 and $300 \mathrm{~W}$. 
annealing of the a-C:H films deposited on the $\mathrm{Si}_{3} \mathrm{~N}_{4}$ substrates was accomplished at $700{ }^{\circ} \mathrm{C}$ in ultrahigh vacuum $\left(10^{-8}\right.$ to $10^{-9}$ torr).

Both in dry nitrogen and in humid air, the initial coefficients of friction for the annealed film deposited at $150 \mathrm{~W}$ (fig. 10(a)) were reduced by about a factor of 2 as compared with those for as-deposited film. The annealed film did not wear off from the substrate in dry nitrogen even after it had been in contact with the rider for about 10000 passes, while in humid nitrogen it wore off at 300 passes and had shorter wear life.

With the a-C:H deposited at $300 \mathrm{~W}$ (fig. 10(b)), the results show an interesting feature: the annealed film exhibited more graphitic behavior; that is, at up to 100 passes the initial coefficients of friction in humid air were lower than those obtained in dry nitrogen. This is contrary to the results obtained from the as-deposited a-C:H films (e.g., fig. 10) and the annealed film at $150 \mathrm{~W}$ power (fig. 10(a)). Further, in the humid air environment the coefficients of friction were reduced by about a factor of 2 as compared with the as-deposited film. The generally accepted theory (that graphite lubricates because of adsorbed water or gaseous films) seems capable of explaining these results [32 and 33]; namely, the a-C:H film deposited at $300 \mathrm{~W}$ is believed to be more graphitic than the films deposited at lower power. Moreover, the annealing of the film gives a more graphitic film. Effective lubrication is possible with the very graphitic film provided both by the high-power plasma deposition and by the annealing process when an adsorbed water vapor film is present. Thus, the annealed a-C:H film deposited at $300 \mathrm{~W}$ has very graphitic friction behavior.

\section{Temperature Effects on Adhesion and Friction in Vacuum}

An increase in the surface temperature of a-C:H films tends to cause chemical changes, as discussed in the preceding subsection. These chemical changes can alter their friction and wear behavior. For simplicity of discussion, the effect of temperature on tribological properties of concern is investigated in a nonoxidizing environment (i.e., in an ultrahigh vacuum). The in situ friction experiments were conducted in a vacuum with the as-received plasma-deposited a-C:H films in contact with the ion-sputter-cleaned, hemispherical monolithic $\mathrm{Si}_{3} \mathrm{~N}_{4}$ rider specimens.

Typical plots of the coefficient of friction for a-C:H films plasma-deposited at 150 and $300 \mathrm{~W}$ as a function of surface temperature are presented in figures 11 (a) and (b), respectively. Comparative data for an uncoated $\mathrm{Si}_{3} \mathrm{~N}_{4}$ flat in contact with a hemispherical $\mathrm{Si}_{3} \mathrm{~N}_{4}$ rider are presented in figure 12.

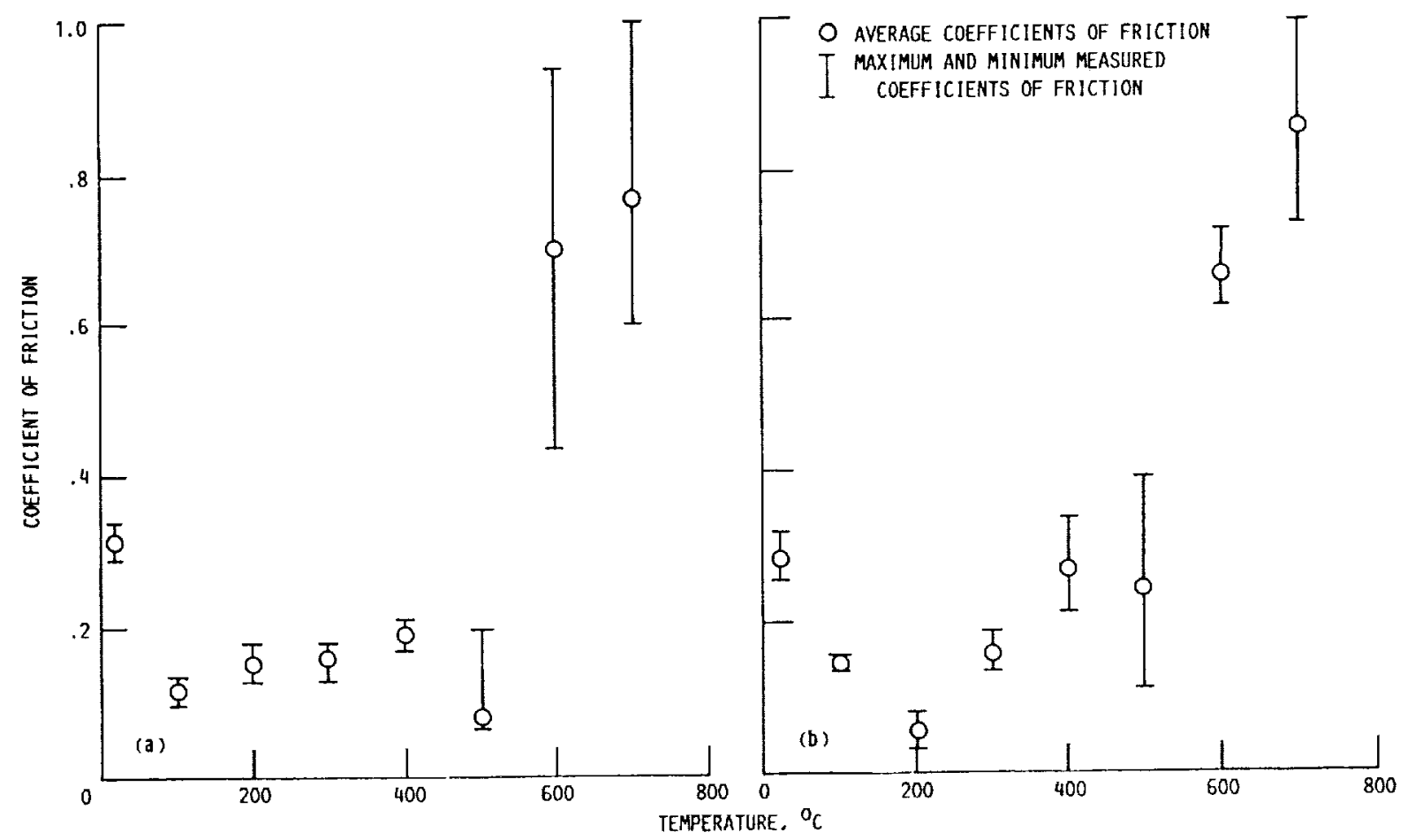

(a) Deposition power, $150 \mathrm{~W}$.

(b) Deposition power, $300 \mathrm{~W}$.

Figure 11.-Coefficients of dynamic friction as function of temperature for a-C:H films in contact with $\mathrm{Si}_{3} \mathrm{~N}_{4}$ rider specimens in vacuum. 


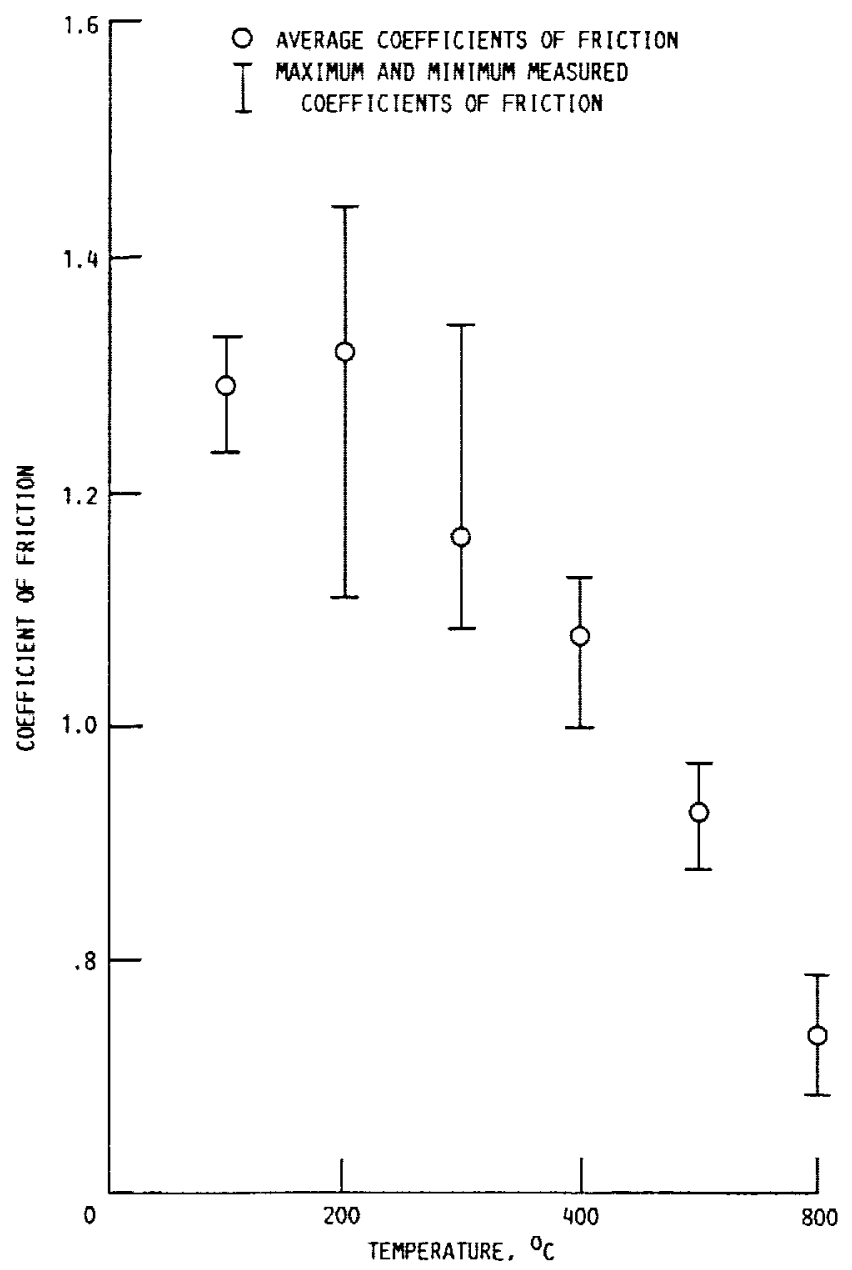

Figure 12.-Coefficients of dynamic friction as function of temperature for $\mathrm{Si}_{3} \mathrm{~N}_{4}$ flats in contact with $\mathrm{Si}_{3} \mathrm{~N}_{4}$ rider specimens in vacuum

With the 150- and 300-W plasma-deposited a-C:H films (fig. 11), the coefficient of friction remained low at temperatures to $500{ }^{\circ} \mathrm{C}$ and rapidly increased with increasing temperatures at $600{ }^{\circ} \mathrm{C}$ and above, remaining high in the range of 600 to $700{ }^{\circ} \mathrm{C}$. The mechanism involved in the rapid increase in friction at 600 to $700{ }^{\circ} \mathrm{C}$ should be related to the two-step process, namely carbonization and polymerization of a-C:H films, as discussed in the preceding subsection.

When compared with the coefficient of friction for $\mathrm{Si}_{3} \mathrm{~N}_{4}$ in contact with $\mathrm{Si}_{3} \mathrm{~N}_{4}$ itself (fig. 12), the coefficient of friction for a-C:H films in contact with a $\mathrm{Si}_{3} \mathrm{~N}_{4}$ rider (fig. 11 ) was generally much lower at temperatures to $500{ }^{\circ} \mathrm{C}$. It is also interesting to note that the coefficient of friction for the film deposited at $150 \mathrm{~W}$ had a very low coefficient of friction (about 0.08 at $500^{\circ} \mathrm{C}$ ) even in an ultrahigh vacuum environment (fig. 11 (a)), and that the film effectively lubricated $\mathrm{Si}_{3} \mathrm{~N}_{4}$ surfaces. Note that in vacuum the friction behavior of a-C:H film deposited at $50 \mathrm{~W}$ was similar to that shown in figure $11(\mathrm{a})$.

\section{CONCLUDING REMARKS}

There are two parts in this chapter, one mainly describing the growth and physical characterization of a-C:H films and the other dealing with the tribological properties. The films can be characterized by several parameters, as described in the first part. The main properties are defined by bonding ratios $\left(s p^{2} / s p^{3}\right)$ and by hydrogen concentration, which will give the graphitic or diamondlike behavior. The more graphitic behavior is associated with lower bandgap and low mechanical etch rate.

In the second part of the work, the a-C:H films were shown to be capable of tribological applications. Plasmadeposited $\mathrm{a}-\mathrm{C}: \mathrm{H}$ can be effectively used as hard, wear-resistant, and protective lubricating films on ceramic material under a variety of environmental conditions such as moist air, dry nitrogen, and vacuum. More specifically, we 
found a very good correlation of the tribological behavior with the physical properties, as described in the first part of the work. For a-C:H films deposited at low power, which are more diamondlike, we found friction behavior similar to that of bulk diamond. The present experiments show that among the a-C:H films deposited at various deposition powers ( 50 to $300 \mathrm{~W}$ ), the film deposited at $50 \mathrm{~W}$ had the lowest initial coefficient of friction in dry nitrogen. The value of the coefficient of friction $(0.08$ to 0.09$)$ was similar to that of hemispherical diamond (radius, $0.2 \mathrm{~mm}$ ) in sliding contact with a $\mathrm{Si}_{3} \mathrm{~N}_{4}$ flat. Conversely, for the a-C:H films deposited at higher power, a graphitic tribological behavior was found. Effective lubrication is possible with the graphitic films like bulk graphite when adsorbed water vapor is present.

Lastly, a simple physical characterization of the films can partially predict the tribological properties.

\section{REFERENCES}

1. Angus, J.J., Koidl, P., and Domitz, S.: "Carbon Thin Films," in Plasma Deposited Thin Films, ed. by Mort. J, and Jansen. F. CRC Press Inc., 1986, pp. 89-127.

2. Aisenberg, S., and Chabot, R.: J. Appl. Phys., 1971, 42, 2953.

3. Holland, L., and Ojha, S.M.: Thin Solid Films, 1978, 48, L21.

4. Berg, S., and Andersson, L.P.: Thin Solid Films, 1979, 58, 117.

5. Meyerson, B., and Smith, F.W.: Solid State Commun., 1980, 34, 531.

6. Moravec, T.J., and Orent, T.W.: J. Vac. Sci. Technol., 1981, 18, 226.

7. Vora, H., and Moravec, T.J.: J. Appl. Phys., 1981, 52, 6151.

8. Banks, B.A., and Rutledge, S.K.: J. Vac. Sci. Technol., 1982, 21, 807.

9. Khan, A.A., Woollam, J.A., Chung, Y., and Banks, B.A.: IEEE Electron Devices Lett., 1983, 4, 146.

10. Khan, A.A., Woollam, J.A., and Chung, Y.: Solid-State Electron., 1984, 27, 385.

11. Kikuchi, M., Hikita, M., and Tamamura, T.: Appl. Phys. Lett., 1986, 48, 835.

12. Pouch, J.J., Warner, J.D., Liu, D.C., and Alterovitz, S.A.: Thin Solid Films, 1988, 157, 97

13. Warner, J.D., Pouch, J.J., Alterovitz, S.A., Liu, D.C., and Lanford, W.A.: J. Vac. Sci. Technol. A, 1985, 3, 900.

14. Alterovitz, S.A., Pouch, J.J., and Warner, J.D.: "Rapid Thermal Annealing of Amorphous Hydrogenated Carbon (a-C-H) Films," in Rapid Thermal Processing of Electronic Materials, MRS Symp. Proc. Vol. 92, ed. by Wilson, S.R., Powell, R., and Davies, D.E., Materials Research Society, 1987, pp. 311-318.

15. Pouch, J.J., Warner, J.D., and Liu, D.C.: Carbon Films Grown from Plasma on III-V Semiconductors. NASA TM-87I40, 1985.

16. Pouch, J.J., Alterovitz, S.A., Warner, J.D., Liu, D.C., and Lanford, W.A.: "Optical Properties of Hydrogenated Amorphous Carbon Films Grown from Methane Plasma," in Thin Films: The Relationship of Structure to Properties, MRS Symp. Proc. Vol. 47, ed. by Aita, C.R. and Sreeharsha, K.S., Materials Research Society, 1985, pp. 201-204 (Also, NASA TM-86995).

17. Alterovitz, S.A., Warner, J.D., Liu, D.C., and Pouch, J.J.: "Ellipsometric and Optical Study of Some Uncommon Insulator Films on III-V Semiconductors," in Dielectric Films on Compound Semiconductors, Electrochemical Society Symp. Proc. Vol. 86-3, ed. by Kapoor, V.J., Connolly, D.J., and Wong, Y.H., The Electrochemical Society, Pennington, NJ, 1986, pp. 59-77 (Also, NASA TM-87135).

18. Pouch, J.J., Alterovitz, S.A., and Warner, J.D.: "Optical and Compositional Properties of a-C:H and BN Films," in Plasma Processing. MRS Symp. Proc. Vol. 68, ed. by Coburn, J.W., Gottscho, R.A., and Hess, D.W., Materials Research Society, 1986, pp. 211-216 (Also, NASA TM-87258).

19. Benninghoven, A.: Surf. Sci., 1975, 53, 596.

20. Wagner, J., Wild, Ch., Pohl, F., and Koidl, P.: Appl. Phys. Lett., 1986, 48, 106

21. Kobayashi, K., Mutsukura, N., and Machi, Y.: J. Appl. Phys., 1986, 59, 910.

22. Kaplan, S., Jansen, F., and Machonkin, M.: Appl. Phys. Lett. 1985, 47, 750.

23. Miyoshi, K., and Rengstorff, G.W.P.: Corrosion, 1989, 45, 266.

24. Miyoshi, K., and Buckley, D.H.: Wear, 1986, 110, 295.

25. Miyoshi, K., Pouch, J.J., Alterovitz, S.A., Pantic, D.M., and Johnson, G.A.: in Wear of Materials, Vol. 2. ed. by Ludema. K.C., ASME, 1989. p. 585.

26. Enke, K., Dimigen, H., and Hubsch, J.: Appl. Phys. Lett., 1980, 36, 291.

27. Memming, R.: Thin Solid Films, 1986, 143, 279.

28. Okada, K., and Namba, Y.: J. Vac. Sci. Technol. A, [989, 7, 132.

29. Bowden, F.P., and Tabor, D.: "The Friction and Lubrication of Solids-Part II," Clarendon Press, Oxford, 1964, pp. 158-185.

30. Prawer, S., Kalish, R., and Adel, M.: Appl. Phys. Lett., 1986, 48, 1585.

31. Robertson, J.: Adv. Phys., 1986, 35, 317

32. Bisson, E.E.: "Nonconventional Lubricants," in Advanced Bearing Technology, ed. by Bisson, E.E. and Anderson, W.J., NASA SP-38, 1965. pp. 203-258.

33. Bisson, E.E., Johnson, R.L., and Anderson, W.J.: "Friction and Lubrication with Solid Lubricants at Temperatures to $1000^{\circ} \mathrm{F}$ with Particular Reference to Graphite," in Proceedings of the Conference on Lubrication and Wear, Institution of Mechanical Engineers, London, England, 1957. pp. 348-354. 


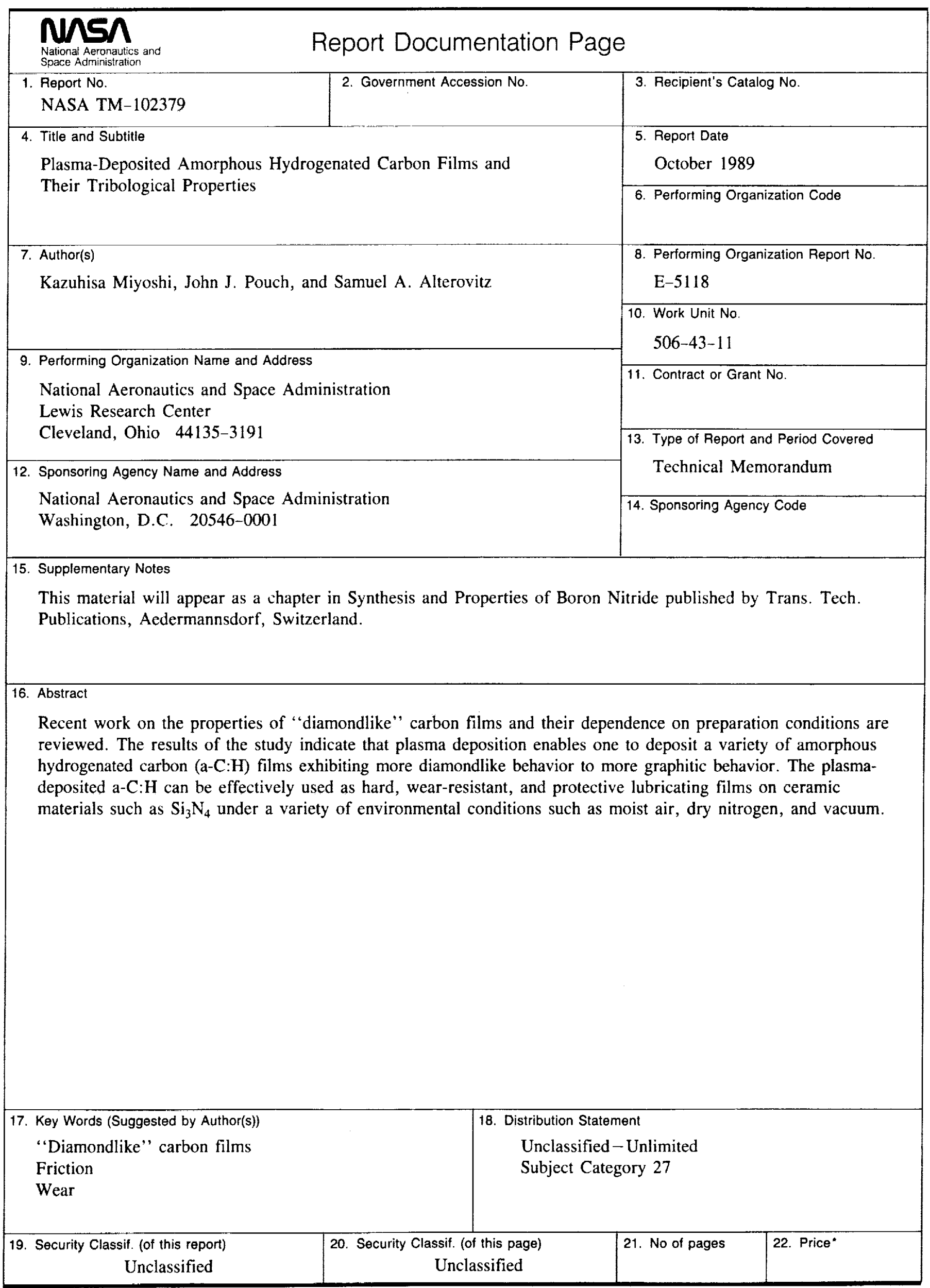

